\title{
Statistical models of interoccurrence times of Iranian earthquakes on the basis of information criteria
}

\author{
Nadia Tahernia ${ }^{1, *}$, Morteza Khodabin ${ }^{2}$, Noorbakhsh Mirzaei ${ }^{3}$ \\ and MORTEZA EsKANDARI-GHADI ${ }^{4}$ \\ ${ }^{1}$ Department of Geophysics, Science and Research Branch, Islamic Azad University, Tehran, Iran. \\ ${ }^{2}$ Department of Mathematics, Karaj Branch, Islamic Azad University, Karaj, Iran. \\ ${ }^{3}$ Institute of Geophysics, University of Tehran, Tehran, Iran. \\ ${ }^{4}$ Department of Engineering Science, Faculty of Engineering, Tehran, Iran. \\ ${ }^{*}$ Corresponding author.e-mail: tahernia@piau.ac.ir
}

\begin{abstract}
By analyzing the seismic catalogue of Iran, the probability distributions of interoccurrence times of earthquakes were investigated for different seismotectonic settings. Several probability distributions were applied to data from major seismotectonic provinces in different cut-off magnitudes and the distribution parameters were determined through the method of maximum likelihood. With the help of goodness-of-fit tests (AIC and BIC criteria based on information theory, Kolmogorov-Smirnov test) and the coefficient of determination, we have found that the gamma statistics and generalized normal statistics coexist in interoccurrence time statistics. Our results imply that a transition from a generalized normal regime to a gamma regime occurs if the threshold magnitude in certain seismotectonic regions (Alborz-Azarbayejan, Zagros, and Central-East Iran) is changed.
\end{abstract}

\section{Introduction}

Earthquakes are phenomena exhibiting great complexity characterized by many empirical statistical laws (Rundle et al 2003; Hasumi et al 2009). Despite this complexity, by neglecting the spatial scale of earthquake rupture zones and the temporal scale of the duration of each earthquake, one can consider the occurrence of earthquakes to be a point process in space and time (Vere-Jones 1970; Ogata 1999; Daley and Vere-Jones 2002; Shcherbakov et al 2005). It is then possible to study the statistical properties of this process and test models that may explain the observed seismic activity (Shcherbakov et al 2005). For the understanding of long-term variation in earthquake occurrences, earthquake predictions, and seismic risk estimates, it is necessary to study the frequency or probability distributions of interoccurrence times of earthquakes (Wang and Kuo 1998).

Early studies led to the conclusion that main sequence events were significantly nonPoissonian, regardless of whether worldwide catalogues (Aki 1956) or local ones (Knopoff 1964; Isacks et al 1967; Singh and Sanford 1972) were considered. Utsu (1984) applied four models (Weibull, gamma, lognormal and exponential) to several seismic regions of Japan and concluded that the four models represent the distributions of interoccurrence times fairly well, though different models are best suited for different sets of data. Recently, a unified scaling law of interoccurrence times was proposed using the Southern California catalogue (Bak et al 2002) and global earthquake

Keywords. Information criteria; interoccurrence time model; seismotectonic province; generalized gamma family; lognormal-gamma transition. 


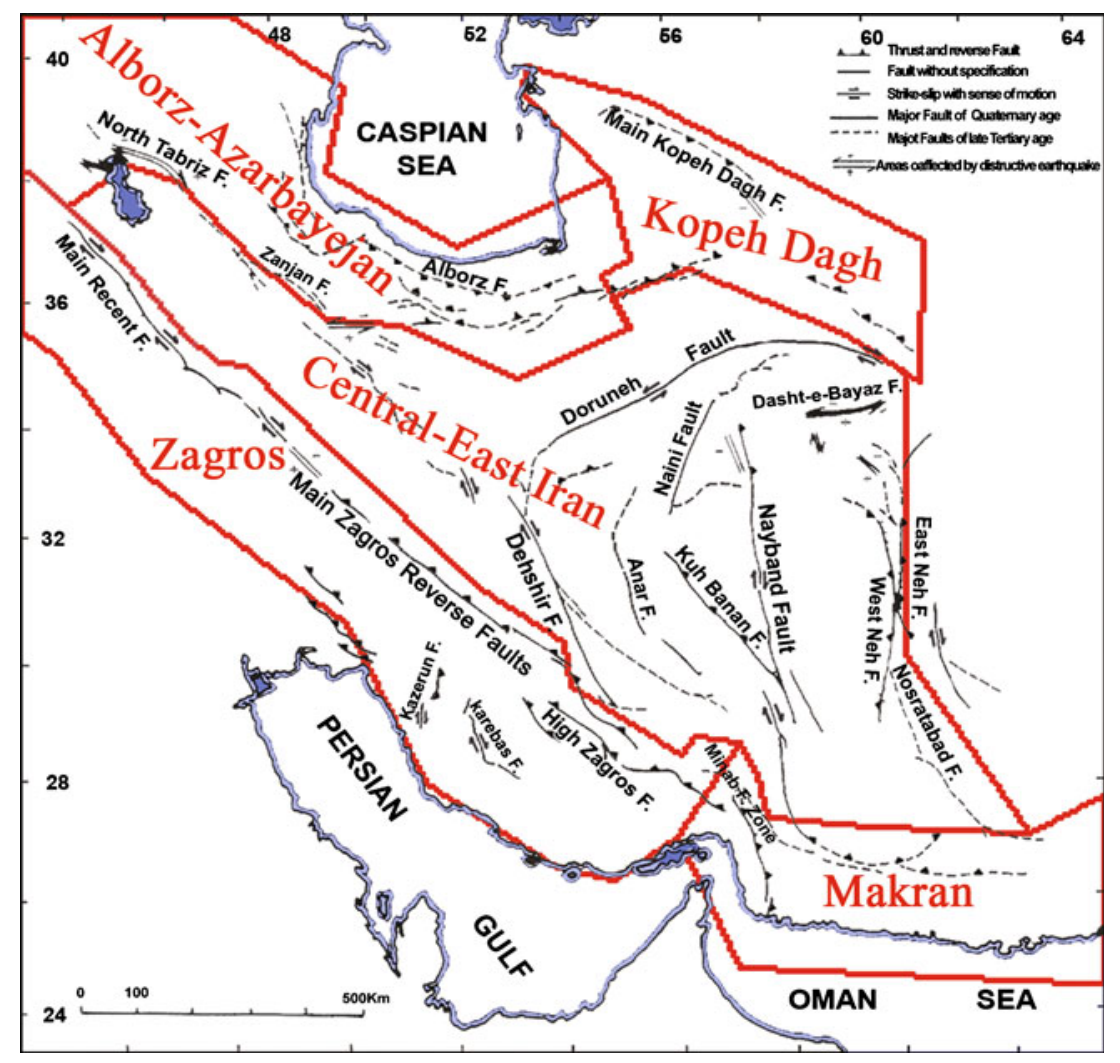

Figure 1. Major seismotectonic provinces of Iran (Mirzaei et al 1998). Selected active faults are also added.

catalogues (Corral 2004). In these works, interoccurrence times were analyzed for the events with a magnitude $(m)$ above a certain threshold where the following two presumptions apply:

- earthquakes can be considered as a point process in space and time;

- there is no distinction between foreshocks, mainshocks, and aftershocks (Hasumi et al 2009).

Abe and Suzuki (2005) showed that the survivor function of the interoccurrence time can be described by a power law. It has been reported that the sequence of aftershocks and successive independent earthquakes is a Poisson process (Nanjo et al 2005; Abaimov et al 2007). Hasumi et al (2009) studied the effect of changing the threshold magnitude on the interoccurrence time statistics by analyzing the Japan Meteorological Agency (JMA) seismic catalogue. They showed that the probability distributions of interoccurrence times of successive earthquakes can be described by the superposition of the Weibull distribution and the $\log$-Weibull distribution.

In this paper, we have paid special attention to seismotectonic features more than the previous works by Bak et al (2002), Lennartz et al (2008), Hasumi et al (2009) and others. The probability distributions of interoccurrence times of earthquakes are studied and the change in interoccurrence time statistics produced by varying of the cut-off magnitude $\left(m_{c}\right)$ is traced; first, in major seismotectonic provinces of Iran (figure 1) and then, in cells of size $L$ degrees in longitude

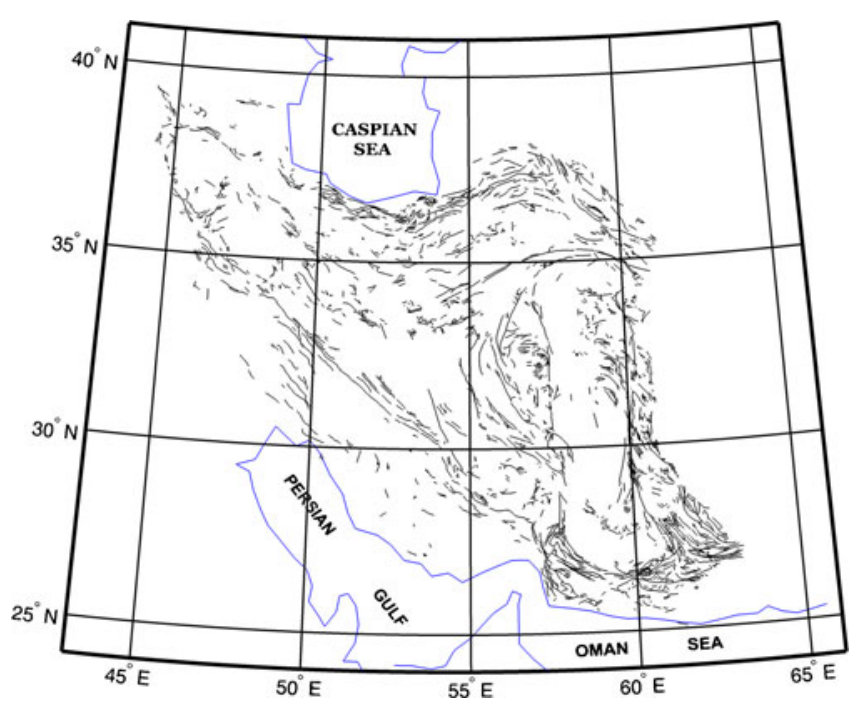

Figure 2. The spatial areas of Iran covered with 12 cells of size $5^{\circ} \times 5^{\circ}$, with no weight assigned to seismotectonic differences. 
and $L$ degrees in latitude which cover the spatial areas of Iran, with no weight assigned to seismotectonic differences (figure 2). Comparison of results displays the effect of region selection in the interoccurrence times of earthquakes.

To determine the distribution function of the interoccurrence times, it was observed that in previous works, gamma, generalized gamma, Weibull, exponential, etc., distributions have been used. All of these are specific cases of generalized gamma (GG) distribution. Consequently, we focused on the GG distribution and subfamilies of it in this study.

Other procedures discussed in this study include fitting distributions to the data, estimation of distribution parameters using the maximum likelihood estimation method and selection of a suitable distribution via the Akaike and Bayesian information criteria, the Kolmogorov-Smirnov test, and the coefficient of determination.

\section{Data analysis and applicable distributions}

In this study, the initial goal is to determine the probability distributions for interoccurrence times of earthquakes with different values of $m_{c}$ in the major seismotectonic provinces of Iran. A seismotectonic province is defined as an area that, under the present-day geodynamic regimes, has a comparable tectonic setting and unified seismicity pattern (Ye et al 1993, 1995). Mirzaei et al (1998) delineated five major seismotectonic provinces in Iran based on available seismicity, geological, tectonic and geophysical information: Alborz-Azarbayejan, Kopeh Dagh, Makran, Zagros and Central-East Iran provinces. Figure 1 shows these major seismotectonic provinces of Iran (Mirzaei et al 1998).

The highly seismic regions of AlborzAzarbayejan covering north and northwest of Iran, which constitute a part of northern limit of Alpine-Himalayan orogenic belt, has experienced intense seismic activity throughout the province during historical and instrumental time periods. In northeast, the continental collision zone of Kopeh Dagh has the lowest level of seismic activity in Iran, but it is characterized by the occurrence of highest portion of large magnitude earthquakes. In the intraplate environment of Central-East Iran, unlike Zagros and Alborz-Azarbayejan, seismicity is mainly concentrated on several seismogenic fault zones surrounding relatively stable microcontinental fragments. East part shows more intense seismicity, in which major seismic activity is concentrated in a few patches. In southwest of
Iran, the continental-continental collision zone of Zagros is seismically very active. It is the most seismic region of Iran (over 50\% of teleseismically recorded earthquakes in Iran have occurred in Zagros). Zagros is characterized by the occurrence of mainly low and moderate intensity earthquakes; there is no record of a great earthquake $\left(M_{s} \geq 8.0\right)$ in this region. In southeast Iran, the oceaniccontinental subduction zone of Makran exhibits a strong segmentation between east and west in the seismic behaviour. The plate boundary in eastern Makran ruptured in the great thrust earthquake of $1945, M_{w}=8.1$, and currently experiences low and moderate intensity earthquakes. In contrast, western Makran exhibits no documented great earthquake. The modern instrumentation shows obvious gap in seismicity along the plate boundary in western boundary.

The earthquake catalogue used in the current study contains occurrence times and hypocentre locations of Iranian earthquakes and is derived from the seismic catalogue published by Mirzaei et al (2002) for earthquakes during 1975-2000. The International Seismological Centre catalogue (www.isc.ac.uk) was used to update the catalogue data up until the year 2008.

In our catalogue, $m_{b}$ or $M_{s}$ or both magnitude scales were assigned to earthquakes. To make the uniform catalogue of earthquakes, $m_{b}$ was converted into $M_{s}$. The $M_{s}-m_{b}$ relationships shown in table 1 were applied to those events for which no $M_{s}$ was assigned, and earthquakes with known $M_{s}$ value were excluded from the conversion and added to the catalogue directly. This earthquake catalogue includes earthquakes with a magnitude of $M_{s} \geq 4.0$ - a value used because complete recording of earthquakes with that magnitude in the major seismotectonic provinces of Iran began in 1975 (Mirzaei et al 1997).

The method of our spatiotemporal analysis is similar to the work of Bak et al (2002), Lennartz et al (2008) and Hasumi et al (2009). However, different information criteria were used to select the appropriate models and more weight has been given to seismotectonic features than all previous works. For each province, earthquakes with magnitude, $M_{s}$ above a certain cut-off magnitude, $m_{c}$, were considered. No events were eliminated; all shocks were considered equally. The interoccurrence times were analyzed and then the data fitting was performed in the time domain. The interoccurrence times of earthquakes were defined using

$$
T_{i}=t_{i}-t_{i-1},
$$

where $T_{i}$ is the time coordinate of the $i$ th earthquake within the province with $m>m_{c}$. 
Table 1. $M_{s}-m_{b}$ relationships for different earthquake regions of Iran (Mirzaei et al 1997).

\begin{tabular}{lll}
\hline Earthquake region & $M_{s}-m_{b}$ relationship & Magnitude range \\
\hline Alborz-Azarbayejan and Kopeh Dagh & $M_{s}=2.01, m_{b}=5.28$ & $4.0 \leq m_{b}<6.2$ \\
Central-East Iran & $M_{s}=1.79, m_{b}=4.32$ & $4.0 \leq m_{b}<6.2$ \\
Zagros & $M_{s}=2.00, m_{b}=5.28$ & $4.1 \leq m_{b}<6.2$ \\
Makran & $M_{s}=1.58, m_{b}=3.11$ & $4.0 \leq m_{b}<5.9$ \\
\hline
\end{tabular}

Table 2. Probability density functions of the generalized gamma and subfamilies of it.

\begin{tabular}{llll}
\hline Distribution & \multicolumn{3}{c}{ Probability density function } \\
\hline Generalized gamma & $P_{\mathrm{GG}}(y \mid \alpha, \tau, \lambda)=\frac{\tau}{\lambda \Gamma(\alpha)}\left(\frac{y}{\lambda}\right)^{\alpha \tau-1} \mathrm{e}^{-\left(\frac{y}{\lambda}\right)^{\tau}}$ & $y \geq 0$ & $\tau, \alpha, \lambda>0$ \\
Exponential & $P_{\mathrm{Exp}}(y \mid \lambda)=\frac{1}{\lambda} \mathrm{e}^{-\left(\frac{y}{\lambda}\right)}$ & $y \geq 0$ & $\lambda>0$ \\
Gamma & $P_{\mathrm{G}}(y \mid \alpha, \lambda)=\frac{1}{\lambda \Gamma(\alpha)}\left(\frac{y}{\lambda}\right)^{\alpha-1} \mathrm{e}^{-\left(\frac{y}{\lambda}\right)}$ & $y \geq 0$ & $\alpha, \lambda>0$ \\
Weibull & $P_{\mathrm{W}}(y \mid \tau, \lambda)=\frac{\tau}{\lambda}\left(\frac{y}{\lambda}\right)^{\tau-1} \mathrm{e}^{-\left(\frac{y}{\lambda}\right)^{\tau}}$ & $y \geq 0$ & $\tau, \lambda>0$ \\
Generalized normal & $P_{\mathrm{GN}}(y \mid \alpha, \lambda)=\frac{2}{\lambda \Gamma(\alpha)}\left(\frac{y}{\lambda}\right)^{2 \alpha-1} \mathrm{e}^{-\left(\frac{y}{\lambda}\right)^{2}}$ & $y \geq 0$ & $\alpha, \lambda>0$ \\
Half-normal & $P_{\mathrm{HN}}(y \mid \sigma)=\frac{\sqrt{2}}{\sigma \Gamma(0.5)} \mathrm{e}^{-\frac{1}{2}\left(\frac{y}{\sigma}\right)^{2}}$ & $y \geq 0$ & $\sigma>0$ \\
Rayleigh & $P_{\mathrm{R}}(y \mid \sigma)=\frac{y}{\sigma^{2}} \mathrm{e}^{-\frac{1}{2}\left(\frac{y}{\sigma}\right)^{2}}$ & $y \geq 0$ & $\sigma>0$ \\
Maxwell-Boltzmann & $P_{\mathrm{MB}}(y \mid \lambda)=\frac{2}{\lambda \Gamma(1.5)}\left(\frac{y}{\lambda}\right)^{2} \mathrm{e}^{-\left(\frac{y}{\lambda}\right)^{2}}$ & $y \geq 0$ & $\lambda>0$ \\
\hline
\end{tabular}

$\Gamma(\cdot)$ is the gamma function, $\alpha$ and $\tau$ are shape parameters and $\lambda$ and $\sigma$ are the scale parameters.

Our main goal in this study is to determine the distribution function of the interoccurrence time.

We focussed on the GG distribution and subfamilies of it such as exponential $(\alpha=\tau=1)$, gamma $(\tau=1)$, Weibull $(\alpha=1)$, lognormal $(\alpha \rightarrow \infty)$ and generalized normal $(\tau=2)$. The generalized normal itself is a flexible family and includes halfnormal $\left(\alpha=1 / 2, \lambda^{2}=2 \sigma^{2}\right)$, Rayleigh $(\alpha=1$, $\left.\lambda^{2}=2 \sigma^{2}\right)$, and Maxwell-Boltzmann $(\alpha=3 / 2)$. (For more details, see Khodabin and Ahmadabadi 2010.) The probability density functions of these distributions are displayed in table 2 . The maximum likelihood estimation (MLE) method was applied to estimate the parameters of above distributions.

In order to detect whether a specific distribution is preferred, three different goodness-of-fit tests were used: Akaike and Bayesian information criteria, and the Kolmogorov-Smirnov test.

Akaike and Bayesian information criteria were used first. Akaike's information criterion (AIC) is a measure of the goodness-of-fit for an estimated statistical model (Akaike 1973, 1974). The AIC is not a test of the model in the sense of hypothesis testing; rather it is a test between models a tool for model selection. Given a dataset, several competing models may be ranked according to their AIC, with the one having the lowest AIC being the best. The Bayesian information criterion
(BIC), or Schwarz criterion, is used for model selection among a class of parametric models with different numbers of parameters. Choosing a model to optimize BIC is a form of regularization and is closely related to AIC. Generally, the AIC and BIC criteria are given by:

$$
\begin{gathered}
\mathrm{AIC}=2 K-2 \log (L(\hat{\theta})) . \\
\mathrm{BIC}=K \log n-2 \log (L(\hat{\theta})) .
\end{gathered}
$$

where $K$ is the number of parameters in the statistical model, $n$ is the number of data, and $L(\hat{\theta})$ is the maximized value of the likelihood function for the estimated model $\left(L(\hat{\theta})=\prod_{i=1}^{n} f_{\theta}\left(x_{i}\right)\right)$.

The Kolmogorov-Smirnov (K-S) test was performed next. This test is used to decide if a sample comes from a hypothesized continuous distribution. It is based on the empirical cumulative distribution function, $F_{n}(x)$, assuming a random sample $x_{1}, \ldots, x_{n}$ from a continuous distribution with a cumulative distribution function, $F(x)$. The $\mathrm{K}-\mathrm{S}$ statistic value $(D)$ is based on the largest vertical difference between $F(x)$ and $F_{n}(x)$. The preferred distribution is the one with the smallest value of $D_{n}$ (D'Agostino and Stephens 1986; Rayner and Best 1989). It is defined as:

$$
D_{n}=\sup _{x}\left|F_{n}(x)-F(x)\right| .
$$


Table 3. Estimated parameters and $A I C, B I C, K-S$ and $R^{2}$ values for different distribution functions and cut-off magnitudes in major seismotectonic provinces of Iran.

\begin{tabular}{|c|c|c|c|c|c|c|c|c|c|c|}
\hline \multirow[b]{2}{*}{ Province } & \multirow[b]{2}{*}{$m_{c}$} & \multirow[b]{2}{*}{ Distribution* } & \multicolumn{4}{|c|}{ Parameters } & \multirow[b]{2}{*}{$\mathrm{AIC}$} & \multirow[b]{2}{*}{$\mathrm{BIC}$} & \multirow[b]{2}{*}{$\mathrm{K}-\mathrm{S}$} & \multirow[b]{2}{*}{$R^{2}$} \\
\hline & & & $\alpha$ & $\lambda$ & $\tau$ & $\sigma$ & & & & \\
\hline \multirow[t]{24}{*}{ Alborz-Azarbayejan } & \multirow[t]{8}{*}{4.0} & Gamma & 0.339 & 115.441 & & & 2504.673 & 2512.152 & 0.052 & 0.994 \\
\hline & & GG & 0.267 & 138.390 & 1.212 & & 2505.549 & 2516.768 & 0.051 & 0.995 \\
\hline & & GN & 0.146 & 194.457 & 2.000 & & 2511.105 & 2518.585 & 0.049 & 0.995 \\
\hline & & Weibull & & 20.212 & 0.465 & & 2527.471 & 2534.950 & 0.084 & 0.981 \\
\hline & & Exponential & & 39.101 & & & 2904.340 & 2908.080 & 0.247 & 0.948 \\
\hline & & Half-normal & & & & 74.350 & 3133.502 & 3137.242 & 0.370 & 0.850 \\
\hline & & Rayleigh & & & & 52.573 & 4514.115 & 4517.855 & 0.518 & 0.709 \\
\hline & & Maxwell & & 60.706 & & & 6012.882 & 6016.622 & 0.587 & 0.642 \\
\hline & \multirow[t]{8}{*}{4.5} & GN & 0.132 & 536.021 & & & 1001.840 & 1007.148 & 0.082 & 0.986 \\
\hline & & GG & 0.076 & 601.855 & 3.318 & & 1002.929 & 1010.891 & 0.079 & 0.988 \\
\hline & & Gamma & 0.286 & 393.065 & & & 1008.285 & 1013.593 & 0.113 & 0.976 \\
\hline & & Weibull & & 50.359 & 0.397 & & 1025.829 & 1031.137 & 0.139 & 0.954 \\
\hline & & Exponential & & 112.603 & & & 1204.012 & 1206.666 & 0.278 & 0.948 \\
\hline & & Half-normal & & & & 194.539 & 1261.249 & 1263.903 & 0.336 & 0.886 \\
\hline & & Rayleigh & & 194.539 & & 137.560 & 1797.395 & 1800.049 & 0.467 & 0.768 \\
\hline & & Maxwell & & 158.840 & & & 2373.432 & 2376.086 & 0.523 & 0.704 \\
\hline & \multirow[t]{8}{*}{5.0} & GN & 0.119 & 1372.390 & & & 464.540 & 468.063 & 0.152 & 0.945 \\
\hline & & GG & 0.098 & 1439.825 & 2.372 & & 466.429 & 471.713 & 0.000 & 0.947 \\
\hline & & Gamma & 0.253 & 1080.403 & & & 467.785 & 471.307 & 0.173 & 0.930 \\
\hline & & Weibull & & 112.050 & 0.350 & & 479.250 & 482.772 & 0.200 & 0.893 \\
\hline & & Exponential & & 273.274 & & & 570.501 & 572.262 & 0.278 & 0.967 \\
\hline & & Half-normal & & & & 472.510 & 594.011 & 595.772 & 0.310 & 0.909 \\
\hline & & Rayleigh & & & & 334.115 & 846.123 & 847.884 & 0.454 & 0.786 \\
\hline & & Maxwell & & 385.803 & & & 1114.571 & 1116.332 & 0.534 & 0.719 \\
\hline \multirow[t]{16}{*}{ Makran } & \multirow[t]{8}{*}{4.0} & Gamma & 0.553 & 224.351 & & & 1104.362 & 1109.511 & 0.043 & 0.998 \\
\hline & & GN & 0.226 & 418.661 & & & 1105.713 & 1110.863 & 0.078 & 0.992 \\
\hline & & GG & 0.414 & 291.289 & 1.242 & & 1105.970 & 1113.694 & 0.080 & 0.997 \\
\hline & & Weibull & & 98.247 & 0.681 & & 1107.063 & 1112.212 & 0.053 & 0.996 \\
\hline & & Exponential & & 124.166 & & & 1131.395 & 1133.970 & 0.144 & 0.981 \\
\hline & & Half-normal & & & & 198.830 & 1169.539 & 1172.113 & 0.276 & 0.918 \\
\hline & & Rayleigh & & & & 140.594 & 1398.817 & 1401.392 & 0.437 & 0.802 \\
\hline & & Maxwell & & 162.344 & & & 1664.948 & 1667.523 & 0.512 & 0.739 \\
\hline & \multirow[t]{8}{*}{4.5} & Gamma & 0.464 & 645.865 & & & 453.226 & 456.337 & 0.084 & 0.987 \\
\hline & & Weibull & & 199.613 & 0.597 & & 453.816 & 456.927 & 0.102 & 0.987 \\
\hline & & GG & 0.822 & 291.166 & 0.674 & & 455.173 & 459.839 & 0.146 & 0.986 \\
\hline & & GN & 0.181 & 1378.172 & & & 458.183 & 461.294 & 0.174 & 0.971 \\
\hline & & Exponential & & 299.506 & & & 471.149 & 472.705 & 0.248 & 0.956 \\
\hline & & Half-normal & & & & 587.023 & 499.060 & 500.615 & 0.389 & 0.828 \\
\hline & & Rayleigh & & & & 415.088 & 613.856 & 615.412 & 0.505 & 0.652 \\
\hline & & Maxwell & & 479.303 & & & 741.950 & 743.505 & 0.589 & 0.553 \\
\hline \multirow[t]{8}{*}{ Kopeh Dagh } & \multirow[t]{8}{*}{4.0} & GN & 0.201 & 368.968 & & & 1249.041 & 1254.548 & 0.047 & 0.997 \\
\hline & & GG & 0.144 & 408.619 & 2.676 & & 1250.838 & 1259.098 & 0.051 & 0.994 \\
\hline & & Gamma & 0.470 & 222.581 & & & 1253.055 & 1258.562 & 0.052 & 0.997 \\
\hline & & Weibull & & 75.830 & 0.605 & & 1261.003 & 1266.510 & 0.070 & 0.993 \\
\hline & & Exponential & & 104.521 & & & 1312.658 & 1315.411 & 0.189 & 0.976 \\
\hline & & Half-normal & & & & 165.552 & 1355.737 & 1358.491 & 0.277 & 0.918 \\
\hline & & Rayleigh & & 165.552 & & 117.063 & 1682.142 & 1684.896 & 0.421 & 0.807 \\
\hline & & Maxwell & & 135.172 & & & 2052.618 & 2055.371 & 0.490 & 0.746 \\
\hline
\end{tabular}

Finally, the coefficient of determination $\left(R^{2}\right)$ was applied. $R^{2}$ is a statistic value that provides information about the goodness-of-fit of a model. This coefficient is the square of the correlation coefficient between the observed and modelled data values. $R^{2}$ will have a value between 0 and 1 . 
Table 3. (Continued).

\begin{tabular}{|c|c|c|c|c|c|c|c|c|c|c|}
\hline \multirow[b]{2}{*}{ Province } & \multirow[b]{2}{*}{$m_{c}$} & \multirow[b]{2}{*}{ Distribution* } & \multicolumn{4}{|c|}{ Parameters } & \multirow[b]{2}{*}{$\mathrm{AIC}$} & \multirow[b]{2}{*}{$\mathrm{BIC}$} & \multirow[b]{2}{*}{$\mathrm{K}-\mathrm{S}$} & \multirow[b]{2}{*}{$R^{2}$} \\
\hline & & & $\alpha$ & $\lambda$ & $\tau$ & $\sigma$ & & & & \\
\hline \multirow[t]{8}{*}{ Kopeh Dagh } & \multirow[t]{8}{*}{4.5} & GN & 0.185 & 1071.669 & & & 505.835 & 509.213 & 0.083 & 0.992 \\
\hline & & Gamma & 0.424 & 671.884 & & & 507.428 & 510.806 & 0.081 & 0.991 \\
\hline & & GG & 0.158 & 1127.434 & 2.288 & & 507.800 & 512.867 & 0.085 & 0.991 \\
\hline & & Weibull & & 194.111 & 0.561 & & 511.260 & 514.638 & 0.088 & 0.987 \\
\hline & & Exponential & & 285.072 & & & 534.219 & 535.908 & 0.207 & 0.964 \\
\hline & & $\mathrm{HN}$ & & & & 460.637 & 550.672 & 552.361 & 0.321 & 0.903 \\
\hline & & Rayleigh & & & & 325.720 & 678.452 & 680.141 & 0.450 & 0.789 \\
\hline & & Maxwell & & 376.109 & & & 821.429 & 823.118 & 0.521 & 0.730 \\
\hline \multirow[t]{24}{*}{ Central-East Iran } & \multirow[t]{8}{*}{4.0} & GN & 0.146 & 179.065 & & & 2506.209 & 2513.727 & 0.058 & 0.995 \\
\hline & & GG & 0.172 & 168.283 & 1.739 & & 2507.894 & 2519.171 & 0.060 & 0.995 \\
\hline & & Gamma & 0.331 & 114.324 & & & 2510.470 & 2517.988 & 0.066 & 0.994 \\
\hline & & Weibull & & 18.604 & 0.454 & & 2529.177 & 2536.695 & 0.078 & 0.987 \\
\hline & & Exponential & & 37.868 & & & 2940.019 & 2943.778 & 0.291 & 0.922 \\
\hline & & Half-normal & & & & 68.444 & 3141.450 & 3145.209 & 0.384 & 0.843 \\
\hline & & Rayleigh & & & & 48.398 & 4549.826 & 4553.585 & 0.521 & 0.722 \\
\hline & & Maxwell & & 55.885 & & & 6078.635 & 6082.394 & 0.578 & 0.668 \\
\hline & \multirow[t]{8}{*}{4.5} & GN & 0.159 & 429.160 & & & 1243.197 & 1248.822 & 0.049 & 0.997 \\
\hline & & Gamma & 0.365 & 267.210 & & & 1244.746 & 1250.370 & 0.052 & 0.996 \\
\hline & & GG & 0.202 & 388.035 & 1.631 & & 1244.869 & 1253.306 & 0.076 & 0.998 \\
\hline & & Weibull & & 54.885 & 0.492 & & 1253.126 & 1258.750 & 0.084 & 0.988 \\
\hline & & Exponential & & 97.594 & & & 1374.881 & 1377.693 & 0.276 & 0.943 \\
\hline & & Half-normal & & & & 171.295 & 1445.818 & 1448.630 & 0.355 & 0.877 \\
\hline & & Rayleigh & & & & 121.124 & 1930.937 & 1933.749 & 0.490 & 0.761 \\
\hline & & Maxwell & & 139.862 & & & 2462.786 & 2465.598 & 0.547 & 0.706 \\
\hline & \multirow[t]{8}{*}{5.0} & Gamma & 0.382 & 640.426 & & & 581.944 & 585.686 & 0.115 & 0.986 \\
\hline & & GN & 0.164 & 1081.538 & & & 582.381 & 586.123 & 0.108 & 0.989 \\
\hline & & GG & 0.270 & 832.506 & 1.322 & & 583.687 & 589.301 & 0.125 & 0.988 \\
\hline & & Weibull & & 141.435 & 0.510 & & 584.103 & 587.846 & 0.142 & 0.981 \\
\hline & & Exponential & & 244.573 & & & 625.953 & 627.825 & 0.322 & 0.931 \\
\hline & & Half-normal & & & & 437.570 & 655.475 & 657.346 & 0.403 & 0.882 \\
\hline & & Rayleigh & & & & 309.409 & 837.762 & 839.633 & 0.488 & 0.781 \\
\hline & & Maxwell & & 357.274 & & & 1038.285 & 1040.156 & 0.543 & 0.725 \\
\hline \multirow[t]{16}{*}{ Zagros } & \multirow[t]{8}{*}{4.0} & GN & 0.176 & 54.656 & & & 5915.847 & 5931.009 & 0.015 & 0.999 \\
\hline & & GG & 0.250 & 46.103 & 1.489 & & 5921.347 & 5930.340 & 0.026 & 0.999 \\
\hline & & Gamma & 0.410 & 32.672 & & & 5926.701 & 5936.363 & 0.050 & 0.996 \\
\hline & & Weibull & & 8.549 & 0.542 & & 5988.929 & 5998.591 & 0.075 & 0.988 \\
\hline & & Exponential & & 13.391 & & & 6659.163 & 6663.994 & 0.223 & 0.965 \\
\hline & & Half-normal & & & & 22.910 & 7145.879 & 7150.710 & 0.310 & 0.905 \\
\hline & & Rayleigh & & & & 16.200 & 10326.360 & 10331.191 & 0.454 & 0.789 \\
\hline & & Maxwell & & 18.706 & & & 13858.644 & 13863.475 & 0.512 & 0.728 \\
\hline & \multirow[t]{8}{*}{4.5} & GN & 0.152 & 190.997 & & & 2453.719 & 2461.561 & 0.049 & 0.994 \\
\hline & & GG & 0.211 & 163.879 & 1.511 & & 2454.166 & 2464.810 & 0.053 & 0.995 \\
\hline & & Gamma & 0.347 & 119.917 & & & 2457.249 & 2464.643 & 0.074 & 0.989 \\
\hline & & Weibull & & 23.173 & 0.475 & & 2491.942 & 2499.336 & 0.100 & 0.975 \\
\hline & & Exponential & & 41.564 & & & 2819.434 & 2823.131 & 0.239 & 0.965 \\
\hline & & Half-normal & & & & 74.433 & 3003.272 & 3006.969 & 0.319 & 0.886 \\
\hline & & Rayleigh & & & & 52.632 & 4258.952 & 4262.649 & 0.459 & 0.747 \\
\hline & & Maxwell & & 60.774 & & & 5627.848 & 5631.545 & 0.534 & 0.674 \\
\hline
\end{tabular}

A value of $R^{2}$ near to 1 indicated that most of the variation of the response data explained by the different input values, whereas a value of $R^{2}$ near to zero indicated that little of the variation of the response data can be explained by the different input values (Ross 2010). The most 
Table 3. (Continued).

\begin{tabular}{|c|c|c|c|c|c|c|c|c|c|c|}
\hline \multirow[b]{2}{*}{ Province } & \multirow[b]{2}{*}{$m_{c}$} & \multirow[b]{2}{*}{ Distribution* } & \multicolumn{4}{|c|}{ Parameters } & \multirow[b]{2}{*}{$\mathrm{AIC}$} & \multirow[b]{2}{*}{$\mathrm{BIC}$} & \multirow[b]{2}{*}{$\mathrm{K}-\mathrm{S}$} & \multirow[b]{2}{*}{$R^{2}$} \\
\hline & & & $\alpha$ & $\lambda$ & $\tau$ & $\sigma$ & & & & \\
\hline \multirow[t]{8}{*}{ Zagros } & 5.0 & GN & 0.158 & 562.596 & & & 945.935 & 950.913 & 0.163 & 0.961 \\
\hline & & GG & 0.120 & 607.119 & 2.560 & & 947.616 & 955.082 & 0.162 & 0.962 \\
\hline & & Gamma & 0.349 & 397.454 & & & 952.463 & 957.440 & 0.188 & 0.946 \\
\hline & & Weibull & & 85.401 & 0.477 & & 970.715 & 975.692 & 0.198 & 0.925 \\
\hline & & Exponential & & 138.543 & & & 1057.750 & 1060.239 & 0.194 & 0.984 \\
\hline & & Half-normal & & & & 223.785 & 1094.293 & 1096.781 & 0.282 & 0.920 \\
\hline & & Rayleigh & & & & 158.240 & 1448.682 & 1451.170 & 0.445 & 0.790 \\
\hline & & Maxwell & & 182.720 & & & 1836.883 & 1839.372 & 0.519 & 0.718 \\
\hline
\end{tabular}

${ }^{*} \mathrm{GN}$ : Generalized normal distribution.

general definition of the coefficient of determination is:

$$
R^{2}=\frac{\sum_{i=1}^{n}\left(f_{i}-\bar{x}_{i}\right)^{2}}{\sum_{i=1}^{n}\left(x_{i}-\overline{x_{i}}\right)^{2}},
$$

where $n$ is the number of data. A dataset has values $x_{i}$, each of which has an associated modelled value $f_{i}$, and $\overline{x_{i}}$ is the mean of the observed data.

\section{Results}

The total number of earthquakes was 1567 in Alborz-Azarbayejan, 213 in Kopeh Dagh, 966 in Central-East Iran, 3620 in Zagros and 228 in Makran. Cut-off magnitude analysis started from $m_{c}=4.0$, and was increased gradually by a rate of 0.1 . An increase in $m_{c}$ signifies a decrease in the number of events in a province. Therefore, in order to limit statistical errors, interoccurrence times were analyzed using at least 50 events.

Different goodness-of-fit tests were used to detect whether a specific distribution was preferred for all regions in all cut-off magnitudes. As an example, the estimated distribution parameters and also the results of AIC, BIC and $\mathrm{K}-\mathrm{S}$ tests and $R^{2}$ for the GG distribution and subfamilies of it at different cut-off magnitudes for five major seismotectonic provinces of Iran are displayed in table 3, where distributions are rearranged based on the results of AIC and BIC tests. To give some examples of plots of the interoccurrence time distributions, together with fitting, using different distribution functions, the cumulative distributions of the interoccurrence times for these provinces, at the same cut-off magnitudes as in table 3 , are displayed in figures $3-7$.

The AIC and BIC criteria are minimax-optimal; they are established based on the likelihood
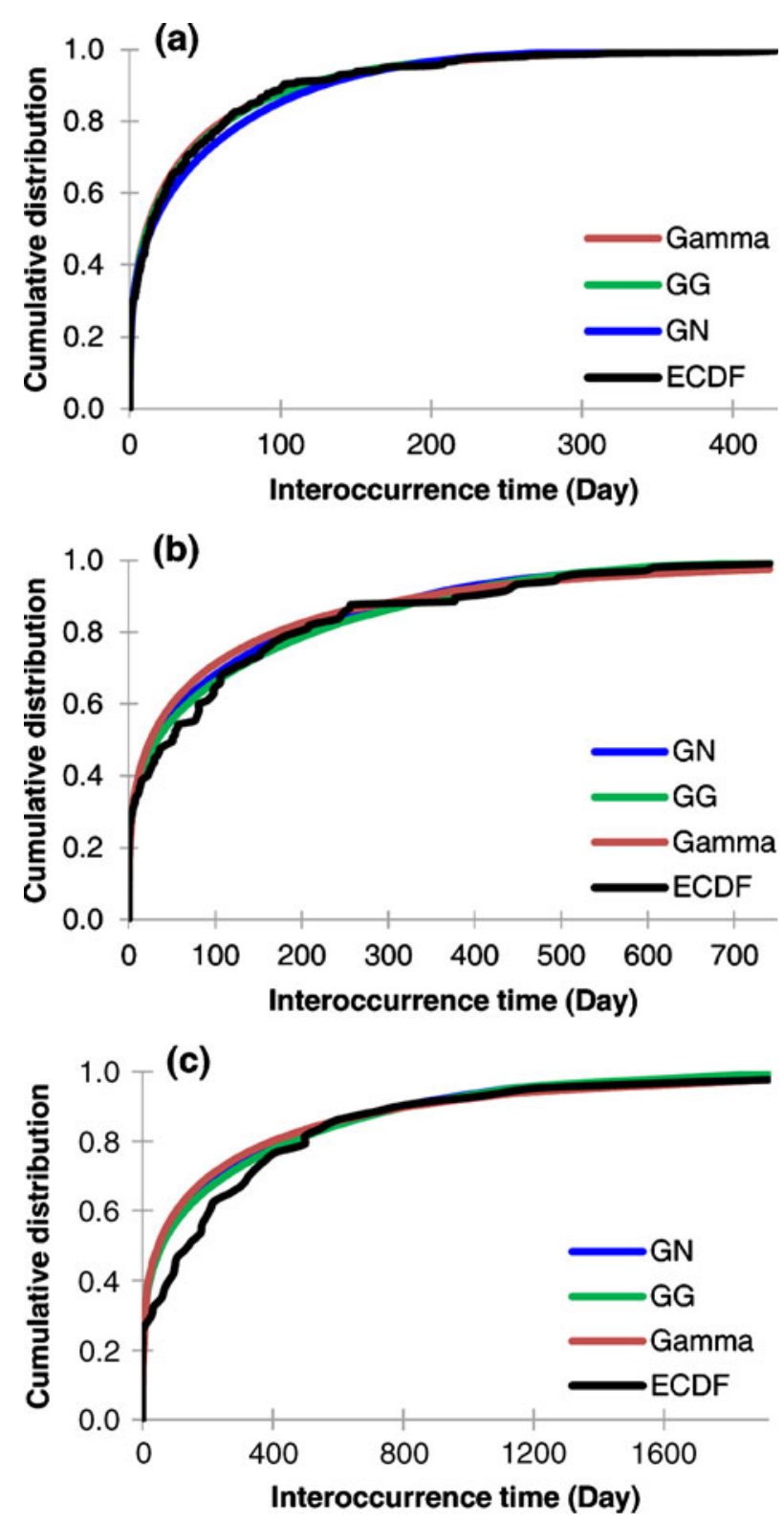

Figure 3. Distribution of interoccurrence time at AlborzAzarbayejan province for different $m_{c}$ and distribution functions: (a) $m_{c}=4.0$; (b) $m_{c}=4.5$; (c) $m_{c}=5$.0. ECDF: Empirical cumulative distribution function. 
function, which is stronger than the coefficient of determination or non-parametric statistics such as the $\mathrm{K}-\mathrm{S}$ statistic. Therefore, in cases that a specified distribution was not the most prominent distribution in all tests, the results of the AIC and BIC tests were considered for selection of the appropriate distribution. Table 4 shows a summary of the selected distributions based on goodness-of-fit test results for different seismotectonic provinces at all cut-off magnitudes.

Further, to compare the result of region selection with respect to seismotectonic features by just covering the region with a grid with $L^{\circ} \times L^{\circ}$ cells, for instance, it is assumed that $L=5^{\circ}$. Generally, for $L$ less than $5^{\circ}$, most of the cells should be omitted from our analysis because of inadequate data. On the other hand, for $L$ more than $5^{\circ}$, the greater part of most of the cells was located outside our study area. By selecting $L=5^{\circ}, 12$ cells extend over the spatial areas of this study, as shown in figure 2. With respect to the existence of sufficient earthquake data in each cell, the regions $45^{\circ}-50^{\circ} \mathrm{E}$ and $25^{\circ}-30^{\circ} \mathrm{N} ; 60^{\circ}-65^{\circ} \mathrm{E}$ and $30^{\circ}-35^{\circ} \mathrm{N}$ and $60^{\circ}-$ $65^{\circ} \mathrm{E}$ and $35^{\circ}-40^{\circ} \mathrm{N}$ were not analyzed. In table 5 , selected distributions for other nine cells are listed for a variety of cut-off magnitudes.
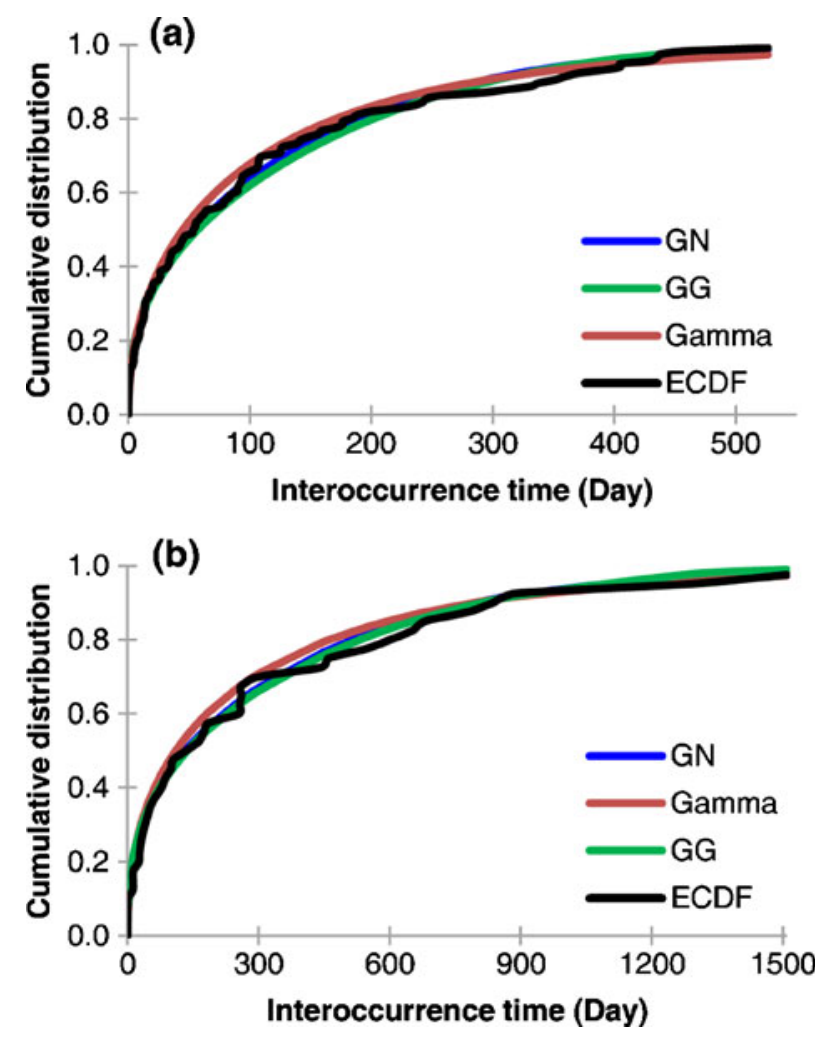

Figure 4. Distribution of interoccurrence time at Kopeh Dagh province for different $m_{c}$ and distribution functions: (a) $m_{c}=4.0$; (b) $m_{c}=4.5$. ECDF: Empirical cumulative distribution function.
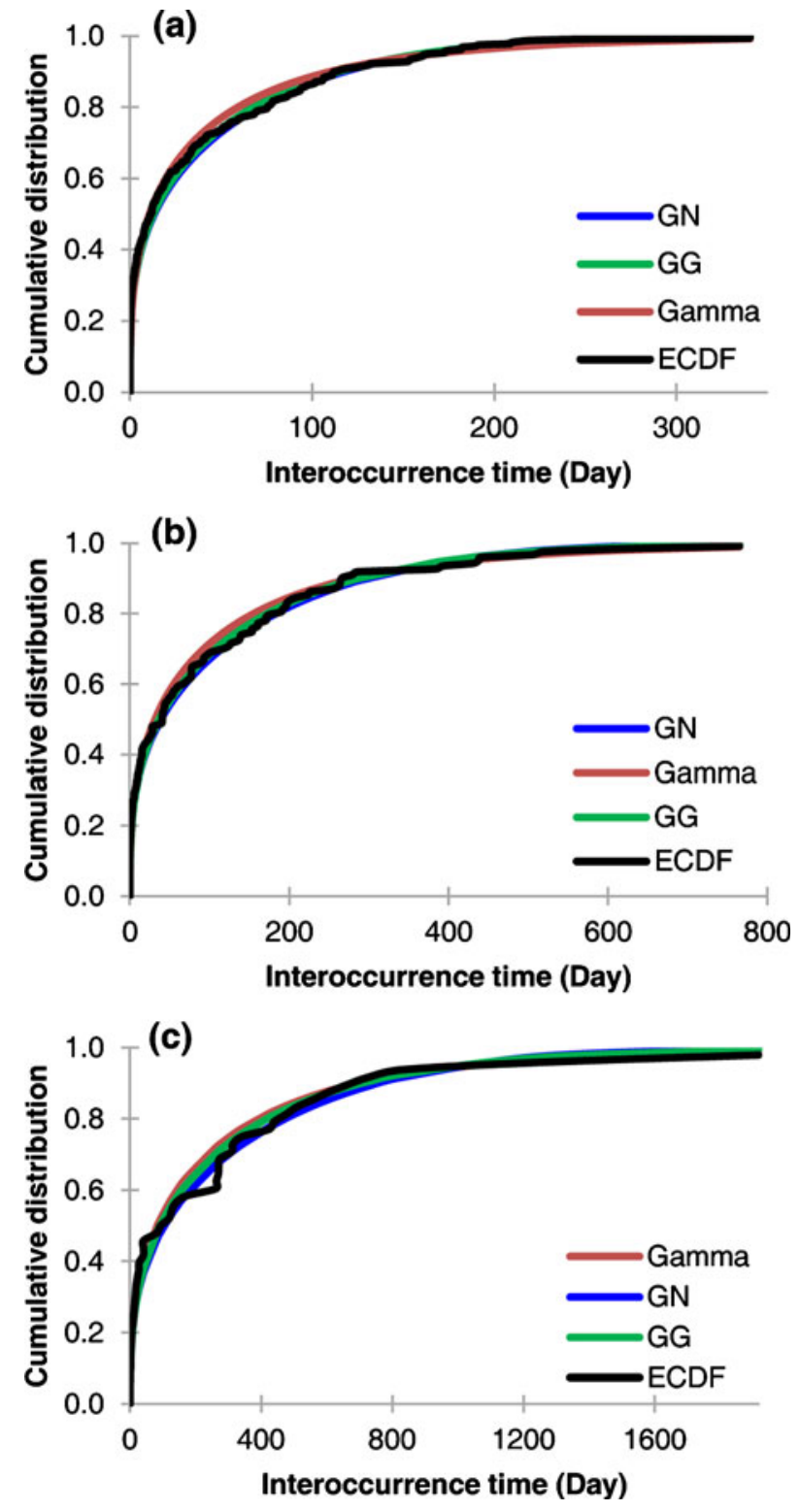

Figure 5. Distribution of interoccurrence time at CentralEast Iran province for different $m_{c}$ and distribution functions: (a) $m_{c}=4.0$; (b) $m_{c}=4.5$; (c) $m_{c}=5.0$. ECDF: Empirical cumulative distribution function.

\section{Discussion}

After focussing on the interoccurrence time distributions of major seismotectonic provinces of Iran, through more testing it became apparent to the researchers that the most suitable distribution for different $m_{c}$ and variety regions is the generalized normal distribution or the gamma distribution (table 4). In general, there is a possibility that the preferred distribution is not unique but dependent on the test used. However, the current results show that in some cases the generalized normal is the 

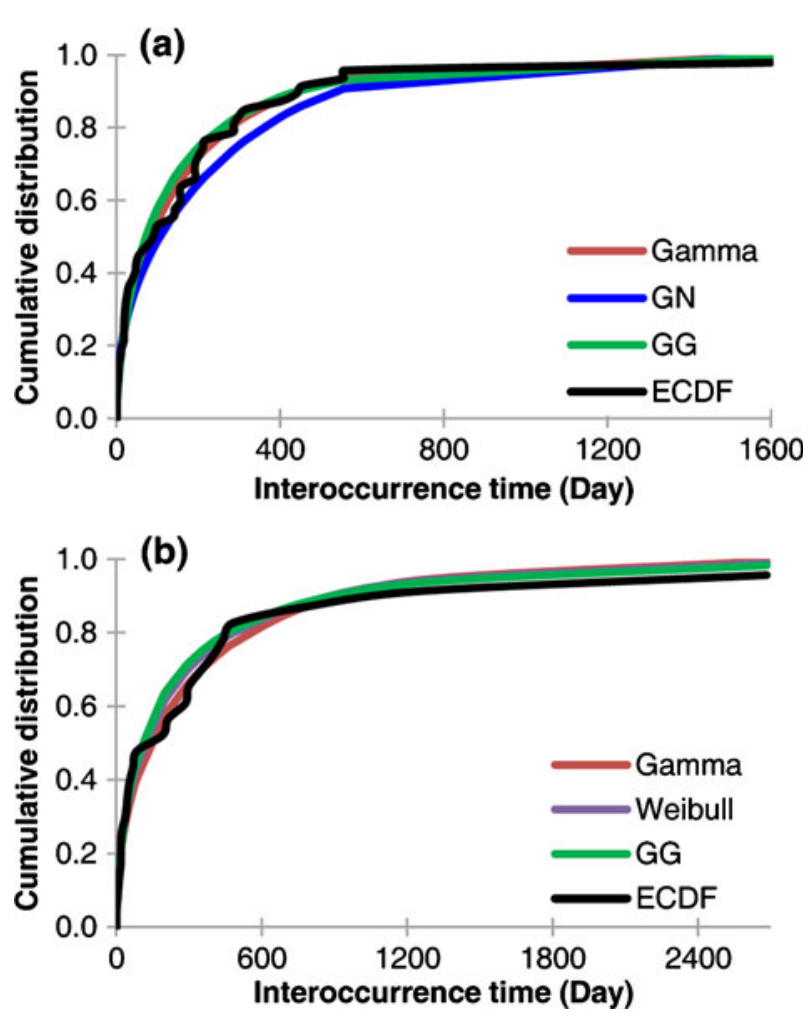

Figure 6. Distribution of interoccurrence time at Makran province for different $m_{c}$ and distribution functions: (a) $m_{c}=4.0 ;$ (b) $m_{c}=4.5$. ECDF: Empirical cumulative distribution function.

most appropriate distribution while for the others, the most suitable distribution is the gamma distribution.

It can be observed that with a gradual decrease in $m_{c}$, the fitting accuracy of the distribution becomes worse in Alborz-Azarbayejan seismotectonic province, and the dominant distribution changes from the generalized normal regime to the gamma regime. The generalized normal distribution showed the best fit to the interoccurrence time data of Kopeh Dagh and Zagros seismotectonic provinces in all threshold magnitudes. In the Central-East Iran seismotectonic province, the most appropriate distribution changes from the generalized normal distribution to the gamma distribution by decreasing $m_{c}$. In all cut-off magnitudes, the gamma distribution was the most suitable for interoccurrence time distribution in the Makran seismotectonic province. It was thus concluded that interoccurrence time statistics exhibit a generalized normal gamma transition in Alborz-Azarbayejan, Zagros and Central-East Iran seismotectonic provinces.

Although, suitable distribution was selected based on the Akaike and Bayesian information criteria, seismicity characteristics have no influences in our choice. We expect various seismicity
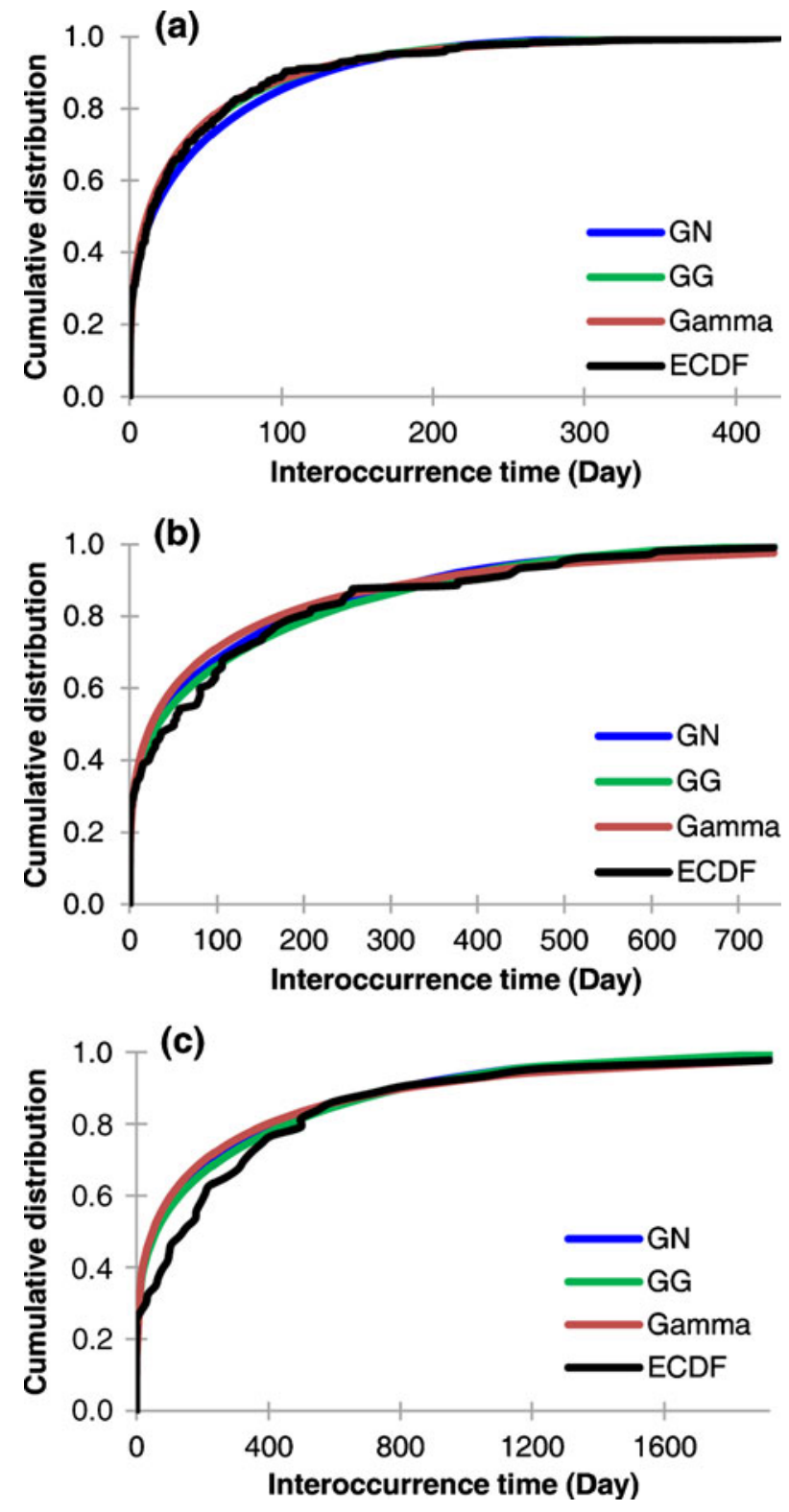

Figure 7. Distribution of interoccurrence time at Zagros province for different $m_{c}$ and distribution functions: (a) $m_{c}=4.0$; (b) $m_{c}=4.5$; (c) $m_{c}=5.0$. ECDF: Empirical cumulative distribution function.

behaviours in different seismotectonic provinces. So, the different suitable distribution of the interoccurrence times and a variety of behaviours in cut-off magnitude changes are not something unexpected.

In this study of the interoccurrence time statistics of cells $\left(5^{\circ} \times 5^{\circ}\right)$ with no seismotectonic feature consideration, in all cells and cut-off magnitudes, the selected distribution based on goodnessof-fit tests result is the gamma or the generalized normal distributions. By changing $m_{c}$, the interoccurrence time statistics exhibit transitions 
Table 4. Selected distributions and estimated parameters for major seismotectonic province of Iran.

\begin{tabular}{|c|c|c|c|c|c|c|c|c|}
\hline \multirow[b]{2}{*}{ Province } & \multirow[b]{2}{*}{$m_{c}$} & \multirow[b]{2}{*}{ Distribution } & \multicolumn{2}{|c|}{ Parameters } & \multirow[b]{2}{*}{$m_{c}$} & \multirow[b]{2}{*}{ Distribution } & \multicolumn{2}{|c|}{ Parameters } \\
\hline & & & $\alpha$ & $\lambda$ & & & $\alpha$ & $\lambda$ \\
\hline \multirow[t]{7}{*}{ Alborz-Azarbayejan } & 4.0 & Gamma & 0.339 & 115.441 & 4.7 & Generalized normal & 0.124 & 861.896 \\
\hline & 4.1 & Gamma & 0.341 & 140.619 & 4.8 & Generalized normal & 0.119 & 1181.906 \\
\hline & 4.2 & Generalized normal & 0.148 & 273.461 & 4.9 & Generalized normal & 0.190 & 1022.436 \\
\hline & 4.3 & Generalized normal & 0.143 & 377.988 & 5.0 & Generalized normal & 0.185 & 1071.669 \\
\hline & 4.4 & Generalized normal & 0.136 & 424.843 & 5.1 & Generalized normal & 0.113 & 1664.108 \\
\hline & 4.5 & Generalized normal & 0.132 & 536.021 & 5.2 & Generalized normal & 0.107 & 1827.592 \\
\hline & 4.6 & Generalized normal & 0.124 & 689.443 & & & & \\
\hline \multirow[t]{3}{*}{ Kopeh Dagh } & 4.0 & Generalized normal & 0.201 & 368.968 & 4.3 & Generalized normal & 0.193 & 713.947 \\
\hline & 4.1 & Generalized normal & 0.198 & 426.112 & 4.4 & Generalized normal & 0.190 & 1022.436 \\
\hline & 4.2 & Generalized normal & 0.197 & 593.884 & 4.5 & Generalized normal & 0.185 & 1071.669 \\
\hline \multirow[t]{7}{*}{ Central-East Iran } & 4.0 & Generalized normal & 0.146 & 179.065 & 4.7 & Generalized normal & 0.172 & 561.973 \\
\hline & 4.1 & Generalized normal & 0.142 & 193.766 & 4.8 & Generalized normal & 0.172 & 691.758 \\
\hline & 4.2 & Generalized normal & 0.144 & 228.289 & 4.9 & Gamma & 0.368 & 560.255 \\
\hline & 4.3 & Generalized normal & 0.151 & 291.588 & 5.0 & Gamma & 0.382 & 640.426 \\
\hline & 4.4 & Generalized normal & 0.159 & 388.216 & 5.1 & Gamma & 0.368 & 707.336 \\
\hline & 4.5 & Generalized normal & 0.159 & 429.160 & 5.2 & Gamma & 0.365 & 676.112 \\
\hline & 4.6 & Generalized normal & 0.174 & 497.905 & & & & \\
\hline \multirow[t]{9}{*}{ Zagros } & 4.0 & Generalized normal & 0.176 & 54.656 & 4.9 & Generalized normal & 0.150 & 461.040 \\
\hline & 4.1 & Generalized normal & 0.170 & 68.368 & 5.0 & Generalized normal & 0.158 & 562.596 \\
\hline & 4.2 & Generalized normal & 0.165 & 75.940 & 5.1 & Generalized normal & 0.154 & 672.751 \\
\hline & 4.3 & Generalized normal & 0.158 & 105.184 & 5.2 & Generalized normal & 0.146 & 827.309 \\
\hline & 4.4 & Generalized normal & 0.155 & 139.848 & 5.3 & Generalized normal & 0.145 & 945.232 \\
\hline & 4.5 & Generalized normal & 0.152 & 190.997 & 5.4 & Generalized normal & 0.129 & 1287.511 \\
\hline & 4.6 & Generalized normal & 0.143 & 278.096 & 5.5 & Generalized normal & 0.132 & 1473.453 \\
\hline & 4.7 & Generalized normal & 0.147 & 319.650 & 5.6 & Generalized normal & 0.114 & 2088.970 \\
\hline & 4.8 & Generalized normal & 0.142 & 381.091 & & & & \\
\hline \multirow[t]{4}{*}{ Makran } & 4.0 & Gamma & 0.553 & 224.351 & 4.4 & Gamma & 0.549 & 446.939 \\
\hline & 4.1 & Gamma & 0.525 & 286.885 & 4.5 & Gamma & 0.464 & 645.865 \\
\hline & 4.2 & Gamma & 0.517 & 363.958 & 4.6 & Gamma & 0.489 & 714.229 \\
\hline & 4.3 & Gamma & 0.544 & 380.356 & & & & \\
\hline
\end{tabular}

between the gamma distribution and the generalized normal distribution in some cells, in the similar fashion to what was observed in the seismotectonic provinces. However, we have not found any regular pattern in cells where these transitions occurred.

Finally, the results were compared with those of the previous studies. The unified scaling law shows a generalized gamma distribution which is approximately a gamma distribution, because $\tau$ in Corral (2004) is close to unity $(\tau=0.98 \pm 0.05)$. However, we have demonstrated that the generalized normal distribution is more appropriate than the gamma distribution, because the AIC and BIC values obtained from the generalized normal distribution are smaller than those of the gamma distribution in most seismotectonic provinces and $m_{c}$. In addition, Hasumi et al (2009) demonstrated that the probability distribution changes by varying the $m_{c}$; in the present study, however, a transition was observed from a generalized normal regime to a gamma regime, which has not been reported previously.

\section{Conclusion}

In this paper, a new feature of interoccurrence time statistics has been proposed by analyzing the earthquake catalogue for different tectonic conditions of Iran. The findings support the view that generalized normal statistics and gamma statistics coexist in the interoccurrence time statistics and with a gradual decrease in $m_{c}$, the fitting accuracy of the dominant distribution becomes worse in some regions. In the Alborz-Azerbaijan seismotectonic province, the predominant distribution changed from the gamma distribution to the generalized normal distribution when $m_{c}$ increased, while in the Central-East Iran seismotectonic province, this change occurred with a decrease in $m_{c}$. In Kopeh Dagh and Zagros seismotectonic 
Table 5. Selected distributions and estimated parameters for different cells.

\begin{tabular}{|c|c|c|c|c|c|c|c|c|}
\hline \multirow[b]{2}{*}{ Region } & \multirow[b]{2}{*}{$m_{c}$} & \multirow[b]{2}{*}{ Distribution } & \multicolumn{2}{|c|}{ Parameters } & \multirow[b]{2}{*}{$m_{c}$} & \multirow[b]{2}{*}{ Distribution } & \multicolumn{2}{|c|}{ Parameters } \\
\hline & & & $\alpha$ & $\lambda$ & & & $\alpha$ & $\lambda$ \\
\hline $25^{\circ}-30^{\circ} \mathrm{N}$ & 4.0 & Generalized normal & 0.179 & 141.282 & 4.4 & Generalized normal & 0.165 & 301.191 \\
\hline \multirow[t]{3}{*}{$50^{\circ}-55^{\circ} \mathrm{E}$} & 4.1 & Gamma & 0.402 & 107.892 & 4.5 & Gamma & 0.366 & 269.226 \\
\hline & 4.2 & Gamma & 0.380 & 138.694 & 4.6 & Generalized normal & 0.154 & 694.273 \\
\hline & 4.3 & Gamma & 0.375 & 183.017 & 4.7 & Generalized normal & 0.153 & 848.554 \\
\hline $25^{\circ}-30^{\circ} \mathrm{N}$ & 4.0 & Generalized normal & 0.136 & 162.224 & 4.5 & Generalized normal & 0.119 & 498.344 \\
\hline \multirow[t]{4}{*}{$55^{\circ}-60^{\circ} \mathrm{E}$} & 4.1 & Generalized normal & 0.135 & 197.410 & 4.6 & Generalized normal & 0.131 & 533.654 \\
\hline & 4.2 & Generalized normal & 0.124 & 270.966 & 4.7 & Generalized normal & 0.132 & 643.777 \\
\hline & 4.3 & Generalized normal & 0.124 & 363.649 & 4.8 & Generalized normal & 0.131 & 766.487 \\
\hline & 4.4 & Generalized normal & 0.120 & 390.195 & 4.9 & Generalized normal & 0.111 & 1059.250 \\
\hline $25^{\circ}-30^{\circ} \mathrm{N}$ & 4.0 & Gamma & 0.513 & 305.371 & 4.2 & Generalized normal & 0.211 & 737.331 \\
\hline $60^{\circ}-65^{\circ} \mathrm{E}$ & 4.1 & Gamma & 0.505 & 342.680 & 4.3 & Gamma & 0.458 & 618.082 \\
\hline $30^{\circ}-35^{\circ} \mathrm{N}$ & 4.0 & Generalized normal & 0.162 & 204.825 & 4.3 & Gamma & 0.324 & 325.726 \\
\hline \multirow[t]{2}{*}{$45^{\circ}-50^{\circ} \mathrm{E}$} & 4.1 & Generalized normal & 0.163 & 249.109 & 4.4 & Generalized normal & 0.141 & 560.203 \\
\hline & 4.2 & Generalized normal & 0.155 & 370.077 & 4.5 & Generalized normal & 0.150 & 715.759 \\
\hline $30^{\circ}-35^{\circ} \mathrm{N}$ & 4.0 & Gamma & 0.473 & 182.551 & 4.3 & Gamma & 0.441 & 375.183 \\
\hline \multirow[t]{2}{*}{$50^{\circ}-55^{\circ} \mathrm{E}$} & 4.1 & Gamma & 0.456 & 243.019 & 4.4 & Gamma & 0.438 & 432.037 \\
\hline & 4.2 & Gamma & 0.453 & 291.213 & 4.5 & Gamma & 0.490 & 479.048 \\
\hline $30^{\circ}-35^{\circ} \mathrm{N}$ & 4.0 & Gamma & 0.281 & 245.211 & 4.3 & Generalized normal & 0.143 & 670.823 \\
\hline \multirow[t]{2}{*}{$55^{\circ}-60^{\circ} \mathrm{E}$} & 4.1 & Generalized normal & 0.124 & 444.335 & 4.4 & Generalized normal & 0.338 & 493.965 \\
\hline & 4.2 & Generalized normal & 0.127 & 543.196 & 4.5 & Gamma & 0.387 & 517.498 \\
\hline $35^{\circ}-40^{\circ} \mathrm{N}$ & 4.0 & Gamma & 0.286 & 307.385 & 4.3 & Generalized normal & 0.125 & 931.319 \\
\hline \multirow[t]{2}{*}{$45^{\circ}-50^{\circ} \mathrm{E}$} & 4.1 & Generalized normal & 0.134 & 576.598 & 4.4 & Generalized normal & 0.122 & 981.188 \\
\hline & 4.2 & Generalized normal & 0.123 & 760.362 & & Generalized normal & & \\
\hline $35^{\circ}-40^{\circ} \mathrm{N}$ & 4.0 & Generalized normal & 0.199 & 429.896 & 4.2 & Generalized normal & 0.200 & 527.128 \\
\hline $50^{\circ}-55^{\circ} \mathrm{E}$ & 4.1 & Generalized normal & 0.199 & 429.896 & 4.3 & Generalized normal & 0.203 & 692.167 \\
\hline $35^{\circ}-40^{\circ} \mathrm{N}$ & 4.0 & Generalized normal & 0.226 & 439.540 & 4.2 & Generalized normal & 0.213 & 634.615 \\
\hline $55^{\circ}-60^{\circ} \mathrm{E}$ & 4.1 & Gamma & 0.519 & 289.539 & & & & \\
\hline
\end{tabular}

provinces, the most suitable distribution was the generalized normal at all threshold magnitudes. The gamma distribution was the most suitable for the interoccurrence time data at a variety of cut-off magnitudes in the Makran seismotectonic province.

\section{Acknowledgement}

This work is partially supported by the Department of Geophysics, Science and Research branch, Islamic Azad University.

\section{References}

Abe S and Suzuki N 2005 Scale-free statistics of time interval between successive earthquakes; Physica A 350 588-596.

Abaimov S G, Turcotte D L and Rundle J B 2007 Recurrence-time and frequency-slip statistics of slip events on the creeping section of the San Andreas fault in central California; Geophys. J. Int. 1701289.

Akaike H 1973 Information theory as an extension of the maximum likelihood principle; In: 2nd Int. Symp.
Inf. Theory (eds) B N Petrov and F Csaki (Budapest: Akademiai Kiado), pp. 267-281.

Akaike H 1974 A new look at the statistical model identification; IEEE Trans. Automat. Contr. 19 716-723.

Aki K 1956 Some problems in statistical seismology; J. Seismol. Soc. Japan (Zisin.) 8 205-228.

Bak P, Christensen K, Danon L and Scanlon T 2002 Unified scaling law for earthquakes; Phys. Rev. Lett. 88 178,501.

Corral A 2004 Long-term clustering, scaling, and universality in the temporal occurrence of earthquakes; Phys. Rev. Lett. 92 108,501.

D'Agostino R B and Stephens M A 1986 Goodness-of-Fit Techniques; Marcel Decker, New York.

Daley D J and Vere-Jones D 2002 Introduction to the Theory of Point Processes; Vol. 1, Elementary Theory and Methods; Springer, New York.

Hasumi T, Akimoto T and Aizawa Y 2009 The Weibull$\log$ Weibull distribution for interoccurrence times of earthquakes; Physica A 388 491-498.

Isacks B L, Sykes L R and Oliver J 1967 Spatial and temporal clusters of deep and shallow earthquakes in Fiji-Tonga-Kermsdec region; Bull. Seismol. Soc. Am. 57 935-958.

Khodabin M and Ahmadabadi A 2010 Some properties of generalized gamma distribution; J. Math. Sci. 4 9-28.

Knopoff L 1964 Statistics of earthquakes in southern California; Bull. Seismol. Soc. Am. 54 1871-1873. 
Lennartz S, Livina V N, Bunde A and Havlin S 2008 Longterm memory in earthquakes and the distribution of interoccurrence times; Europhys. Lett. 81 69,001.

Mirzaei N, Gao M and Chen Y T 1998 Seismic source regionalization for seismic zoning of Iran: Major seismotectonic provinces; J. Earthquake. Pred. Res. 7 465-495.

Mirzaei N, Gao M, Chen Y T and Wang J 1997 A uniform catalog of earthquakes for seismic hazard assessment in Iran; Acta Seismol. Sinica 10 713-726.

Mirzaei N, Gheitanchi M R, Naserieh S, Raeesi M, Zarifi Z and Tabaei S G 2002 Basic parameters of earthquakes in Iran; Danesh Negar Publications, Tehran.

Nanjo K Z, Turcotte D L and Shcherbakov R 2005 A model of damage mechanics for the deformation of the continental crust; J. Geophys. Res. 110 B07403.

Ogata Y 1999 Seismicity analysis through point-process modelling: A review; Pure Appl. Geophys. 155 471507.

Rayner J C W and Best D J 1989 Smooth Tests of Goodness of Fit; Oxford University Press.

Ross S M 2010 Introductory Statistics; 3rd edn, Academic Press.

Rundle J B, Turcotte D L, Shcherbakov R, Klein W and Sammis C 2003 Statistical physics approach to understanding the multiscale dynamics of earthquake fault systems; Rev. Geophys. 411019.

Shcherbakov R, Yakovlev G, Turcotte D L and Rundle J B 2005 Model for the distribution of aftershock interoccurrence times; Phys. Rev. Lett. 95 218,501.

Singh S and Sanford A R 1972 Statistical analysis of microearthquakes near Socorro, New Mexico; Bull. Seismol. Soc. Am. 62 917-926.

Utsu T 1984 Estimation of parameters for recurrence models of earthquakes; Bull. Earthquake Res. Inst. Univ. Tokyo $5953-66$.

Vere-Jones D 1970 Stochastic models for earthquake occurrence; J. Roy. Stat. Soc. B (Methodological) 32 1-62.

Wang J H and Kuo C H 1998 On the frequency distribution of interoccurrence times of earthquakes; J. Seismol. 2 351-358.

Ye H, Chen G G and Zhou Q 1995 Study on the intraplate potential seismic sources; Proc. 5th Intl. Conf. Seismic Zonation, Nice, France, pp. 1424-1430.

Ye H, Zhou Y D, Zhou Q, Yang W L, Chen G G and Hao C T 1993 Study on potential seismic sources for seismic zonation and engineering seismic hazard analysis in continental areas; IASPEI Publication Series for the IDNDR 3 473-478. 